\title{
P. REZAKHANI
}

\section{A REVIEW OF FUZZY RISK ASSESSMENT MODELS FOR CONSTRUCTION PROJECTS}

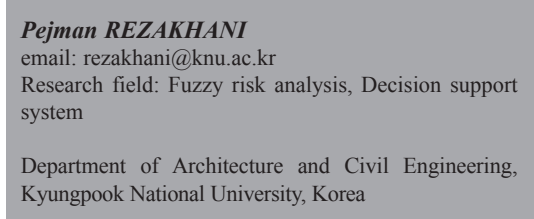

INFORMATION

\section{ABSTRACT}

Risk modeling and analysis is one of the most important stages in a project's success. There are many approaches for risk assessment, and an investigation of existing methods helps in developing new models. This paper is an extensive literature survey in risk modeling and analytic methods with a main focus on fuzzy risk assessment.

\section{KEY WORDS}

- Risk modeling,

- Fuzzy risk assessment,

- Project risk.

\section{INTRODUCTION}

A "risk" is defined as the potential for complications and problems with respect to the completion of a project and the achievement of a project goal (Mark, et al., 2004). It is an uncertain future event or condition with an occurrence rate of greater than $0 \%$ but less than $100 \%$, which has an effect on at least one of a project's objectives (i.e., scope, schedule, cost, or quality, etc.). In addition, the impact or consequences of this future event must be unexpected or unplanned (Chia, 2006). It is well accepted that risk can be effectively managed to mitigate its' adverse impacts on project objectives, even if it is inevitable in all project undertakings. Sources of risk include inherent uncertainties and issues relative to a company's fluctuating profit margin, the competitive bidding process, weather changes, job site productivity, political situations, inflation, contractual rights, market competition, etc. (Karimiazari, et al., 2011). It is important for construction companies to face these uncertain risks by assessing their effects on a project's objectives because the quantitative risk method allows for deciding which aspects of a project are more risky, planning for the potential sources of risk in each project, and managing each source during construction (Zayes, Amer and Pan, 2008). It is noteworthy that risk is distinguished from uncertainty. The one is measurable uncertainty; the other is immeasurable risk (Hillson, 2004; Olsson, 2007; Karimiazari, et al. , 2011).

Therefore, managing risk is involved in identifying, assessing and prioritizing risks by monitoring, controlling, and applying managerial resources with a coordinated and economical effort so as to minimize the probability and/or impact of unfortunate events and so as to maximize the realization of project objectives (Douglas, 2009). Project risk management, which has been practiced since the mid-1980s, is one of the nine main knowledge areas of the Project Management Institute's project management body of knowledge (Tuysz, et al., 2006). Effective risk management may lead a project manager to achieve several benefits such as identification of a favorable alternative course of action, increased confidence in achieving a project's objectives, improved chances of success, reduced surprises, more precise estimates (through reduced uncertainty), reduced duplication of effort (through team awareness of risk control actions), etc. (Bannerman, 2008). 
Systemic project risk management has an effect on a project's success. It has been found that there is a strong relationship between the amount of risk management efforts undertaken in a project and the level of the project's success (Elkington and Smallman, 2002; Reza, et al., 2002). Several project risk management approaches have been proposed as follows: PRAM (Chapman, 1997); RAMP (Institute of Civil Engineering, 2002), PMBOK (PMI 2008); RMS (Institute of Risk Management, 2002) (Nieto, et al., 2011). Existing approaches may be summarized as a four-phase process for effective project risk management, i.e., identifying, assessing, responding, and monitoring and/or reviewing risks. Identifying risks is the first step which determines which risk components may adversely affect which project objectives and documents their characteristics (Karimiazari, et al., 2011). Construction risks are classified in many ways by risk types (i.e., natures and magnitudes, etc.), the sources and/or origins, or the project phase (Cooper and Chapman, 1987; Edwards and Bowen, 1998; Klemetti, 2006; Zhou, et al., 2008). Some present-day researchers propose a hierarchical structure of risks, which classifies risks according to their origin and the location at which the risk impacts on the project (Tah, et al., 1993; Wirba, et al., 1996).

Assessing risks is a step which prioritizes the risks for further analysis by quantifying their occurrence rates. The risk assessment method is an essential component of this step. The existing methods are classified into (1) simple classical methods, and (2) advanced mathematical models (Karimiazari, et al., 2011). The existing risk assessment methods are either qualitative or quantitative and require different information and levels of detail (Bennett, et al., 1996). The simple classical methods integrate deterministic risk modeling and analysis into CPM scheduling. The deterministic methods include sensitivity analysis (White, 1995), the critical path method (Kaufmann and Gupta, 1998), fault tree analysis (Terano, Asai and Sugeno, 1992), event tree analysis (Huang, Chen and Wang, 2001), failure modes, and effects and criticality analysis, etc. (Bowles and Pelaez, 1995). Other advanced approaches have been proposed as follows: a Monte Carlo Simulation (White, 1995) for stochastic quantitative modeling and analysis; a scenario analysis (Rainer, et al., 1991), and fuzzy set theory for qualitative judgments (Rainer, et al., 1991). There are many factors which should be considered when a project risk manager selects a risk assessment method, i.e., the cost of employing the technique, the level of any external party`s approval, the organizational structure, agreement, adoptability, complexity, completeness, level of risk, organizational size, organizational security philosophy, consistency, usability, feasibility, validity, credibility, and automation (Lichtenstein, 1996). It is essential for a risk manager to have high-quality data in order to effectively apply quantitative methods, even if it is not easy to obtain

Tab. 1 Key expertise for risk analysis by project phase ${ }^{l}$.

\begin{tabular}{|c|c|c|c|c|}
\hline Discipline & Planning & Preliminary & Final Design & Construction \\
\hline Planning & $\bullet$ & $\bullet$ & O & \\
\hline Environmental & $\bullet$ & $\bullet$ & O & O \\
\hline Funding Approval & $\bullet$ & $\bullet$ & O & \\
\hline Project Management & $\bullet$ & $\bullet$ & $\bullet$ & $\bullet$ \\
\hline Engineering & $\bullet$ & $\bullet$ & $\bullet$ & $\bullet$ \\
\hline Civil, Structural, Systems & O & O & $\bullet$ & $\bullet$ \\
\hline Cost Estimating & O & $\bullet$ & $\bullet$ & $\bullet$ \\
\hline Scheduling & O & $\bullet$ & $\bullet$ & $\bullet$ \\
\hline Budgeting Controls & O & O & $\bullet$ & O \\
\hline Real Estate/Right of Way & O & $\bullet$ & $\bullet$ & O \\
\hline Construction Management & O & O & $\bullet$ & $\bullet$ \\
\hline Constructability/Contractor & O & O & O & $\bullet$ \\
\hline Other Technical & O & $\bullet$ & $\bullet$ & $\bullet$ \\
\hline Risk Facilitation & - & - & - & 0 \\
\hline
\end{tabular}

- Highly Desirable

O Desirable but optional depending upon the circumstances

1 Adapted from NCHRP 8-60: Guidebook on Risk Analysis Tools and Management, 2009 
such high quality data relative to the risk items in the construction industry. This difficulty is attributed to the need to address the uncertainties and subjectivities associated with construction activities (Zeng, et al., 2007). Besides the lack of collectability, the uniqueness and non-repetitive nature of construction projects impede using probabilistic risk quantification approaches (Baloi and Price, 2003).

Responding to risks is involved in developing options and/or actions to enhance opportunities to achieve a project's objectives. Finally, monitoring and reviewing risks is necessary to implement a risk response plan, keep track of the risks identified, monitor residual risks, identify new risks, and evaluate the effectiveness of the project risk management process (Nieto, et al., 2011). For this step, each engineering expert should use the specialized risk management tool as shown in Table 1 for a risk analysis depending on the project's phases.

\section{FUZZY RISK ASSESSMENT}

After Zadeh (1965) introduced the concept of fuzzy sets and theory, researchers such as Kangari (1988), Kangari and Riggs (1989), Peak, et al., (1993), Tah and McCaffer (1993), Wirba, et al. (1996), Carr and Tah (2001), Cho, et al. (2002), Choi, et al. (2004), Lyons and Skitmore (2004), Baker and Zeng (2005), Dikmen, et al. (2007), Zeng, et al. (2007), Wang and Elang (2007), Karimiazar, et al. (2011), and Nieto, et al. (2011) introduced fuzzy set theory (FST)based risk modeling and analytic methods that deal with ill-defined, vague, imprecise, and complex risk analysis problems. For example, Kangari (1988) proposed the application of fuzzy theory in a risk analysis method using linguistic terms. The fuzzy theory-based risk analysis method was implemented as a part of a construction project risk management system which consists of five steps (i.e., risk identification, policy definition, risk sharing and allocation, risk analysis, and risk minimization and response planning, etc). The fourth component, risk analysis, consists of the following three steps: natural language computation, fuzzy set risk evaluation, and linguistic approximation.

Kangari and Riggs (1989) present a risk analysis model (1989), which makes use of Fuzzy set theory (FST) as a risk assessment tool, consisting of three modes as follows: natural language computation, a fuzzy set's evaluation of risk, and linguistic approximation (Taroun, et al., 2011). Specifically, the linguistic approximation method handles subjectivity issues in construction risk assessments by finding the nearest natural language expression for the estimated fuzzy set numbers using Euclidean distance. Peak, et al. (1993) proposed a risk pricing model that determines the bid price of a construction project. The model estimates the risk-associated consequence as fuzzy numbers, which represent risk consequences to reflect the uncertainty involved in determining the bid price. The fuzzy numbers are assumed by two intervals; i.e., the most likely and the largest likely intervals, which are obtained from either historical data or expert opinions. The model applies fuzzy arithmetic operations to compute the risk contingency value and a ranking method to calculate the value of the risk contingency in terms of the monetary cost by transferring the fuzzy number into a crisp value. The method was verified by applying it to a real construction project.

Tah and McCaffer (1993) introduced a computer tool which approximates the amount of the contingency cost in PASCAL programming. The system determines the risk level in linguistic terms to be used as the basis of the contingency allocation for tender preparations. It proposes a new risk breakdown structure called a "hierarchical risk-breakdown structure" (HRBS), which presents a contractor's risk. Wirba, et al. (1996) presented a fuzzy set theorybased risk assessment approach which identifies risks, checks for dependencies amongst them, and assesses the risk`s likelihood of occurrence by using linguistic variables.

Carr and Tah (2001) presented a fuzzy set-based qualitative risk assessment model which implements a hierarchical risk breakdown structure. The model allows for the definition of the risk descriptions and their consequences using linguistic variables and formulation of the rules using the relationship between the likelihood of occurrence (L), the severity (V), and the effect of the risk factor (E), i.e., "If $L$ and $V$, then E." Fuzzy approximation and composition were performed to identify and quantify the relationship between the risk sources and the consequences to the project's performance measures. It evaluates the risk exposure by assessing the consequences relative to the project's performance measures (i.e., time, cost, quality and safety, etc.) using the fuzzy estimates of the risk components. Cho, et al. (2002) proposed an uncertainty range estimate method, which incorporates uncertainties using fuzzy concepts. The method introduces some forms of fuzzy membership functions which represent the degree of uncertainties involved in both probabilistic parameter estimates and subjective judgments. The method uses linguistic variables (i.e., "close to any value" or "higher/lower than the analyzed value," etc.), which include some quantification that gives the specific value by defining three membership functions (i.e., "close to," "lower than," and "higher than" curves).

Choi, et al. (2004) presented a fuzzy-based uncertainty assessment system which considers uncertainty as objective probabilities and subjective judgment by incorporating probabilistic or linguistic variables. The system was rigorously tested with an underground construction. It implements four steps, i.e., identifying, analyzing, evaluating and managing the risks inherent in construction 
projects. It was confirmed that the system accommodated both probabilistic data obtained from the historical data and subjective data obtained from an expert group. An, et al. (2005), proposed a risk assessment or risk management system for a construction project. This system also proposed a risk analysis method as a part of the risk management system developed. Dikmen, et al. (2007) proposed a fuzzy risk rating method, which rates the risk involved in cost overruns in international construction projects. The model introduces "Controllability" or "Manageability" concepts into the contractor's decision making which determines if the contractor enters into the international market. It allows for the assessing of the contractor's decision using four categories, i.e., internationalization, market selection, project selection, and markup selection. The system identifies risks, models the risks using influence diagrams, selects the membership function of each variable, captures the experts' opinions using aggregation rules, aggregates fuzzy rules into a fuzzy cost overrun risk rating, carries out fuzzy operations, and determines the risk level of an international project by quantifying the final risk rating.

Zeng, et al. (2007) hybridized fuzzy reasoning and the AHP approach to handle subjective assessments and prioritize diverse risk factors, respectively (Taroun, et al. 2011). The model quantifies the risk magnitude (RM) of risk by integrating a risk parameter called the factor index (FI), which evaluates the magnitude of the possible risk and combines it with the risk likelihood (RL) and risk severity (RS) into a fuzzy inference system. The system utilized a modified fuzzy AHP to capture and convert the expert's fuzzy information and subjective judgment. Wang and Elang (2007) proposed a fuzzy multi-criteria and multi-participant decision-making approach, which allows decision makers to rapidly and effectively evaluate multiple fuzzy risk factors using linguistic terms by aggregating the assessments of multiple risk factors. Zhang and Zou (2007) proposed a methodology which produces the appraisal vector of the risky conditions of a construction project by aggregating the weight coefficient of any risk groups and fuzzy risk factors obtained from experts using the AP technique, a hierarchical structure of risks, and the fuzzy evaluation matrixes of risk factors. Nieto, et al. (2011) proposed an algorithm to handle the inconsistency in the fuzzy preference relation when pair-wise comparison judgments are necessary. Karimiazari, et al. (2011) proposed an extended version of the Technique for Order Preference by Similarity to an
Ideal Solution (TOPSIS), which resolves the multi-criteria risk assessment model under a fuzzy environment.

\section{CONCLUSION}

Lyons and Skitmore (2004) described the common procedure that all fuzzy risk assessment methods retain as follows: the first step, the definition and measurement of parameters, defines the risk probability and the risk severity with which a project is assessed in linguistic terms and converts them into corresponding fuzzy numbers. The second step, the definition of a fuzzy inference, defines the relations between the input parameters and output parameters in "if-then" rules or mathematical functions using an appropriate fuzzy arithmetic operator. The final step, defuzzification, converts the fuzzy result into an exact numerical value.

These and other researchers have recommended taking into account the imprecision, vagueness, and fuzziness of the risk factors in a construction project to appropriately deal with a contractor's project risks by using Fuzzy Set Theory (FST). It is well accepted that Fuzzy Set Theory (FST) provides a useful way to deal with ill-defined and complex problems in decision making by quantifying imprecise information, incorporating vagueness, and making decisions based on imprecise and vague data. The method allows for the translation of a subjective judgment given in linguistic expressions (i.e., "low," "high," etc.) into mathematical measures. Dikmen, et al. (2007) mentions that FST is commendable for project-based industries because it is almost impossible to use probabilistic methods due to the unique nature of construction undertakings. The rational to use FST in project risk assessment is as follows: first, the modeling of vague input is successfully done with the use of membership functions. Second, the inherent ability of FST to explain its reasoning ensures that the modeling process is understood and can also be intuitively verified. Third, the parallel nature in which rules are activated in a fuzzy system ensures that all the factors are considered in a harmonized manner. Fourth, the results of fuzzy systems can naturally be scaled to be comparable with each other with the use of the scaling membership functions. Finally, fuzzy logic's use of linguistic sets and rules ensures that the terminology of the user interface and modeling structure can be tailored towards specific environments. 


\section{REFERENCES}

[1] An M., Baker C., and Zeng, J., (2005), A Fuzzy Logic-Based Approach to Qualitative Risk Modeling in the Construction Process, World Journal of Engineering, 2, 1-2.

[2] Baloi, D., and Price, A. D. F. (2003). Modeling global risk factors affecting construction cost performance, International Journal of Project Management, 21, 261-269.

[3] Bannerman, P. L. (2008). Risk and risk management in software projects: A reassessment. The Journal of Systems and Software, 81(12), 2118-2133.

[4] Bennett, J.C, Bohoris, G.A., E.M. (1996), Aspinwall, R.C. Hall, Risk analysis techniques and their application to software development, European Journal of Operation Research, 95, 467-475.

[5] Bowles, J. B., and Pelaez, C. E. (1995). Fuzzy logic prioritization in a system failure mode, effects and criticality analysis, Reliability Engineering and System Safety, 50, 203-213.

[6] Chapman, C., (1997). Project risk analysis and management - the PRAM generic process, International Journal of Project Management, 15, 273-281.

[7] Chia, S.E. (2006). Risk assessment framework for project management. IEEE, 376-379.

[8] Cho, H. N., Choi, H. H., and Kim, Y. B. (2002). A risk assessment methodology for incorporating uncertainties using fuzzy concepts. Reliability Engineering and System Safety, 78, 173-183.

[9] Choi, H., Cho, H., and Seo, J. W. (2004). Risk assessment methodology for underground construction projects. Journal of Construction Engineering and Management, 130(2), 258-272.

[10] Cooper, D.F., Champan, C.B., (1987). Risk Analysis for a Large Project.Wiley, Chichester.

[11] Dikmen, I., Birgonul, M., Han, S., (2007). Using fuzzy risk assessment to rate cost overrun risk in international construction projects. International Journal of Project Management, 25, 494-505.

[12] Douglas, Hubbard (2009). The failure of risk management: Why it's broken and how to fix it. John Wiley and Sons, p. 46

[13] Elkington, P., and Smallman, C. (2002). Managing project risks: A case study from the utilities sector. International Journal of Project Management, 20, 49-57.

[14] Hillson, D. (2004). Effective opportunity management for projects - exploiting positive risk. New York: Marcel Dekker

[15] Huang, D., Chen, T., and Wang, M.-J. (2001). A fuzzy set approach for event tree analysis. Fuzzy Sets and Systems, 118, 153-165.
[16] Institute of Risk Management, (2002). A risk management. Standard Institute of Risk Management.

[17] Institution of Civil Engineers, (2002). Risk Analysis and Management for Projects (RAMP). Institution of Civil Engineers and Faculty and Institute of Actuaries. Thomas Telford, London.

[18] Kangari, R. (1988), Construction Risk Management, Civil Engineering System, 5, September 1988.

[19] Kangari, R. and Riggs, L.S (1989) Construction Risk Assessment by Linguistics, IEEE Transaction on Engineering Management, 36(2), 126-131.

[20] KarimiAzari, et al. (2011). Risk assessment model selection in construction industry, Expert Systems with Applications, 38, 9105-9111.

[21] Kaufmann, A., and Gupta, M. M. (1988). Fuzzy mathematical models in engineering and management science. Amsterdam: North-Holland.

[22] Klemetti, A. (2006). Risk management in construction project networks. Report 2006/ 2. Finland: Laboratory of Industrial Management, Helsinki University of Technology.

[23] Lichtenstein, Sh. (1996). Factors in the selection of a risk assessment method. Information Management and Computer Security, 4, 20-25.

[24] Nieto-Morote, A., Ruz-Vila, F., (2011). A fuzzy approach to construction project risk assessment, International Journal of Project Management, 29, 220-231

[25] Olsson, R. (2007). In search of opportunity management: Is the risk management process enough? International Journal of Project Management, 25, 745-752.

[26] Paek, J.H., Lee, Y.W. and Ock, J.H (1993). "Pricing Construction Risks: Fuzzy Set Theory" Journal of Construction Engineering and Management, 119(4), 743-756.

[27] Project Management Institute, (2008). A guide to the project management body of knowledge. Project Management Institute Standards Committee.

[28] Rainer, R.K.J.R., Snyder, C.A., Carr, H.H. (1991) Risk analysis for information technology, Journal of Management Information Systems, 8 (1), 129-147.

[29] Raz T, Shenhar AJ, Dvir D. (2002). Risk management, project success, and technological uncertainty. R\&D Management, 32, 101-109.

[30] Tah, J.H.M., Thorpe, A., McCaffer, R., (1993). Contactor project risks contingency allocation using linguistic approximation. Computing System in Engineering, 4, 281-293. 


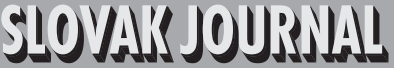 \\ (1) \\ (d)IL}

2012/3 PAGES $35-40$

\section{REFERENCES}

[31] Taroun, A., Yang, J.B., Lowe, D., (2011). Construction Risk Modeling and Assessment: Insights from a Literature Review, The Built and Human Environment Review, Volume 4, Special Issue 1.

[32] Terano, T., Asai, K., and Sugeno, M. (1992). Fuzzy systems theory and its applications. San Diego, CA: Academic Press.

[33] Tuysuz and Kahreman (2006). Project Risk Evaluation Using a Fuzzy Analytic Hierarchy Process: An Application to Information Technology Projects, International Journal of Intelligent Systems, 21, 559-584

[34] Wang, Y.M., Elhag, T.M.-S., (2007). A fuzzy group decision making approach for bridge risk assessment. Computers and Industrial Engineering, 53, 137-148.

[35] White, D. (1995). Application of systems thinking to risk management: A review of the literature. Management Decision, 3(10), 35-45.
[36] Wirba, E.N., Tah, J.H.M., Howes, R., (1996). Risk interdependencies and natural language computations. Journal of Engineering, Construction and Architectural Management, $3,251-269$

[37] Zadeh, L.A., (1965). Fuzzy sets. Information Control 8, 338-353.

[38] Zeng, J., An, M., and Smith, N. J. (2007). Application of a fuzzy based decision making methodology to construction project risk assessment. International Journal of Project Management, 25, 589-600.

[39] Zhang, G., Zou, P.X.W., (2007). Fuzzy analytical hierarchy process risk assessment approach for joint venture construction projects in China. Journal of Construction Engineering and Management 133, 771-779. 